\title{
E-BUSINESS AND THE FORMATION OF STRATEGIES
}

\author{
SVEN JUNGHAGEN ${ }^{1}$ and HENRIK C. J. LINDEROTH ${ }^{2}$ \\ ${ }^{1}$ Department of Management, Politics \& Philosophy, Copenhagen Business School \\ ${ }^{2}$ Department of Management, Politics \& Philosophy, Copenhagen Business School and Centre \\ for Digital Business, Umeå School of Business and Economics
}

Abstract: During the last years e-business has become a topic that has gained much attention among scholars and practitioners, and in contemporary business different IT-applications play important roles for transactions in business to business (B2B) relations. But in business to consumer (B2C) relations the results of e-business efforts are mixed. Hence, the issue is what kind of strategic considerations a company has to do when they would engage in ebusiness efforts on $\mathrm{B} 2 \mathrm{C}$ relations? The aim of the paper is to discuss a few possible points of departure for a further inquiry into the relation between a company's strategies and e-business efforts, that could be important to pay attention to in further research on e-business and strategies, or when a company would conduct an e-business effort. The discussion takes its point of departure in different theoretical conceptions on strategy, with the intention to account for a model on strategy formation that can be valid in relation to ebusiness in $\mathrm{B} 2 \mathrm{C}$ relations. The theoretical concepts are then discussed with regards to some s observations mainly build on secondary data. Built on the secondary data and the theoretical conception on strategy formation, the following topics are identified to be highlighted in the process of relating ebusiness efforts to a overall strategies: (1) A clear conception of the target market, (2) A consistency between the defined market and the product system to be sold, (3) An understanding of the relation between market, product and the delivery/communication system, (4) Act on the values and beliefs of the organisation.

The original version of this chapter was revised: The copyright line was incorrect. This has been corrected. The Erratum to this chapter is available at DOI: 10.1007/978-0-387-35692-1_36 


\section{INTRODUCTION}

During the last years e-business has become a topic that has gained much attention among scholars and practitioners, and in contemporary business different IT-applications play important roles for transactions in business to business (B2B) relations. But in business to consumer (B2C) relations the results of e-business efforts are mixed. From a strategic point of view, management dealing with $\mathrm{B} 2 \mathrm{C}$ relations seems to consider how the company would be related to e-business. Should the company enter the e-business scene, or should it stay outside? If a decision is made to enter the e-business scene, the management issue will than be formulation and implementation of e-business efforts.

Recommendations for formulation and implementation of e-business efforts are varying from a process of rigorous planning (see e.g. Hackbart \& Kettinger 2000), to an organic process (Brache \& Webb 2000). Consequently, it does not seems to be a best way of formulating e-business efforts in B2C relations, but can some common topics be identified for a formulation of e-business efforts? In order to elaborate upon this issue a few perspectives on generic business strategies will be discussed in this paper. Concepts discussed in the theoretical framework will be combined with some empirical observations mainly build secondary data, with the aim of identify and discuss topics that could be important to pay attention to in further research on e-business and strategies, or when a company would conduct an e-business effort. Thus, the aim of the paper is to discuss a few possible points of departure for a further inquiry into the relation between a company's strategies and e-business efforts.

In order to reach this aim, some basic virtues of a company is discussed, which is followed by a discussion on different theoretical conceptions on strategy, with the intention to account for a conceptual framework on strategy formation that can be valid in relation to e-business. This discussion is followed by some observations of e-business attempts, built mainly on secondary data from descriptions of e-business efforts, and a few informal interviews. The following analyses will account for a discussion on these observations in relation to the theoretical framework with the purpose to indicate some possible directions in the quest for integration of e-business efforts into a company's overall strategies.

\section{BASIC VIRTUES OF THE FIRM}

To put it bluntly, it could be claimed that e-business strategies are completely uninteresting, but e-business as strategy is very interesting. It 
might seem to be a matter of rhetoric, but solely discussing e-business strategies could in fact be to get into implementation issues, without questioning the basic premises of the chosen path. The discourse on the new e-conomy has been characterised by a strong technological imperative. A predominant part of the literature on e-business and e-commerce has taken its starting point in concepts like e.g. richness and reach in terms of technological possibilities (e.g. Evans \& Wurster, 2000) and more or less neglected other traditional business virtues. We do however believe that even though a new e-conomy might be expired today, some basic marketing virtues and strategic virtues are to be remembered and honoured.

One of the most fundamental virtues is that of value creation. Even though it might seem as a very simplified view of a firm, it can stated that if a firm cannot provide a value that someone outside the firm is willing to pay for, the firm will inevitably die. Even if first mover advantage is expired or if a firm have an extensive amount of unique hits on your website, it will not survive without someone willing to pay for what you do. This statement is one important starting point for our perspective on strategy. Another important issue is the relation between overall business strategies and ebusiness efforts. E-business can be seen as a very broad concept including all activities in a firm, if these activities are in some way incorporated in a digital information system. The focus in this paper will be on activities related to the external relations of a firm, and mainly activities supporting transactions with consumers by means of the Internet. It might be a blunt description, but it can be claimed in a marketing and strategy perspective that the Internet can be seen as a media for communication and for transactions. In some cases, if the product is virtual, it can also be seen as a distribution channel. Put in other words, the Internet can be seen as a communications resource, a content resource and a channel resource (Coupey, 2001). As claimed above, a high amount of hits on a website do not necessarily lead to success automatically, but will enable the site owner to sell this exposure to advertisers. We will not in this paper go into these mechanisms, where Internet can be seen as a pure communications media through an attractive content. Instead, the discussion will focus on strategy formation options in relation to the conception of Internet as a strategic channel resource for products and services, and to illuminate interdependencies of e-business efforts and overall strategies of a firm. 


\section{A THEORETICAL CONCEPTION OF STRATEGY FORMATION}

\subsection{A Discourse on Strategy}

Strategy might be one of these words we use a lot, without a single unified conception of the "true meaning" of the word. The word strategy is directly derived from the Greek word strategia, basically meaning the art of warfare in a supreme command position. Early conceptions of business strategy and corporate strategy are very much related to this basic meaning of the word. Strategy is something that you practice in a command position in a firm, to plan a competitive action against opponents in a market or an industry. The holder of this command position is in Greek called strategos. Even though we do not agree fully with the analogy of warfare, there are some dimensions in this generic derivation that deserve attention. First of all, even though there are not enemies, strategy can be seen as something dealing with the external relations of a firm. This might be in competition with others, in co-operation, and even in co-opetition (e.g. Hamel, Doz \& Prahalad, 1989). Secondly, even though strategy might not be a phenomenon specifically addressed to a supreme command, it should be regarded as some kind of guided action, by means of a vision, a mission or intent (e.g. Campbell \& Yeung, 1991).

The discourse on strategy is clearly diversified, with a number of paradigms and perspectives. Mintzberg et al. (1998) suggest ten schools of thought on strategy, a classification involving thoughts of scholars as well as practitioners. We are not going into all these schools of thoughts in this paper, but the two major categories are worth mentioning, the prescriptive and the descriptive schools of thought. Examples of the prescriptive schools are the planning school and the positioning school, where the fundamental logic of strategy formation is a distinction between decision-making and the implementation of these decisions. Mintzberg also refers to this category as deliberate strategies.

As a reaction to the fact that these normative statements seldom seemed to come true, the descriptive schools of thought on strategy emerged. Instead of giving normative propositions, the descriptive schools rather propose how things actually are done. Examples here are the cognitive school, the environmental school and the learning school. In these schools of thought, strategies are not deliberate, but emergent. Even though it might seem that these different conceptions of strategy are conflicting in terms of explaining the strategy phenomenon, it could argued that the conflict is not on a factual 
level, but an ideological level. The most important difference is in ontological assumptions. The prescriptive schools are based on an objective ontology, where it is possible to analyse a context and make a decision that will provide a satisfactory outcome. Most of the descriptive schools are more subjective in their ontological assumption, and strategy is formed as for example a consequence of social constructions (e.g. Searle, 1995) as in the cognitive school, or through individual psychological characteristics (e.g. Davidsson 1989; 1996; Thong \& Yap, 1995) as in the entrepreneurial school or through collective learning, and so forth.

The main problem in the debate between these schools is that the validation of the explanatory power in the perspective is based on the ontological assumptions underlying the same perspective. In a way, validation tends to be a self-fulfilling prophecy. We do not intend to take an active part in that debate in this paper, but try to provide a theoretical conception of interdependency between e-business and overall strategies that can function as a prescriptive statement based on a view that strategies emerge, rather than are planned.

\subsection{The Concept of Business Ideas}

A conceptual framework that can function as an overall model of strategy formation is that of business ideas (Normann, 1975). A business idea could be seen as a statement defining the raison d'être for a firm, answering three basic questions: To whom, what, and How? The answers to these three questions include a close description of the specific market, the product system delivered to this market, and finally the system of resources, competencies and structures utilised in order to make it all happen.

The most important part is not just a clear conception of these three levels, but a high level of consistency between the levels. You might have a clear conception of a given market, and the perfect product for this market, but if you do not have a consistent system for delivery, you will not succeed. 


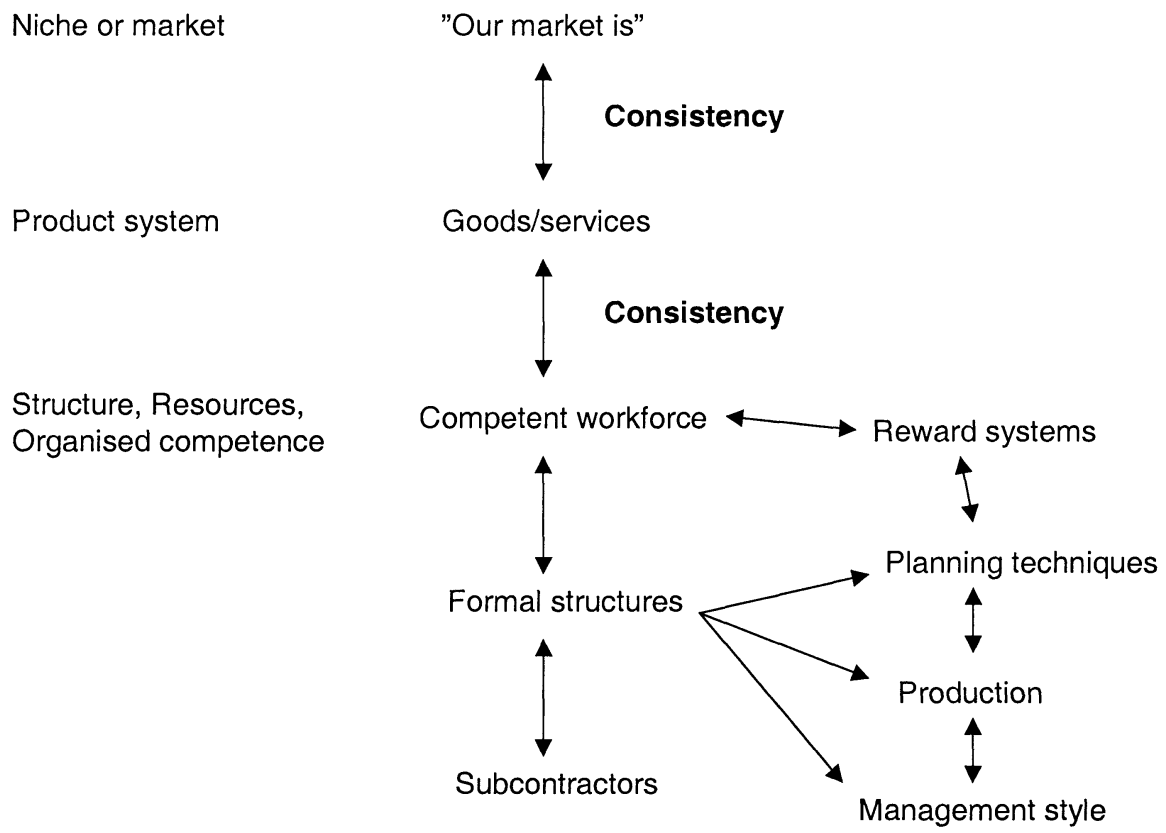

Figure 1. Main characteristics of a business idea (Normann, 1975)

As was stated above, someone outside the firm must perceive the offer as valuable in order for the firm to survive on a long-term basis. A critical reflection might evolve at this stage, since discussions on infrastructure and other structural resources are normally sorted under a discourse on operations management and not strategic management, but that is very much dependent upon a chosen perspective. We believe in inseparability between these elements, the duality of strategy and structure (e.g. Chandler, 1962) basically meaning that we cannot tell whether strategy forms structure or if structure forms strategy. As a consequence, the argument in the introductory section is strengthened, where it was stated that e-business efforts should take overall business strategies into account and support them. By extending this line of reasoning even further, if we believe in inseparability between strategy and supporting structures, e-business efforts should not just support overall strategies, but be an integrative part of strategy formation.

\subsection{Strategy formation}

If we then direct our focus to formation on a conceptual level, rather than formulation and implementation, it might seem problematic to accept 
emergent strategies, and in the same time state that e-business efforts should be an integrative part. We do however believe in that strategies emerge within a more or less explicitly defined sense of strategic direction of the firm. As claimed above, this sense of direction could for example be defined through the business idea. The question is then if this implies that a change of strategic direction simply means that the business idea should be reformulated? In order for that to be true, we have to believe in the possibility to plan an action to be implemented later. Since we do not accept that belief, we have to answer negatively and will instead bring forward a model showing the relation between intentions for future change and present conditions. The model shown in figure 2 is built on a conception that there is a relation between the change situation, the organisational structure and the system of values and beliefs in the firm. Any intended change has to take the existing structure and values into account. The values and beliefs of significant actors regarding the identity of the firm may for example be as important for the potential for change as market conditions are.

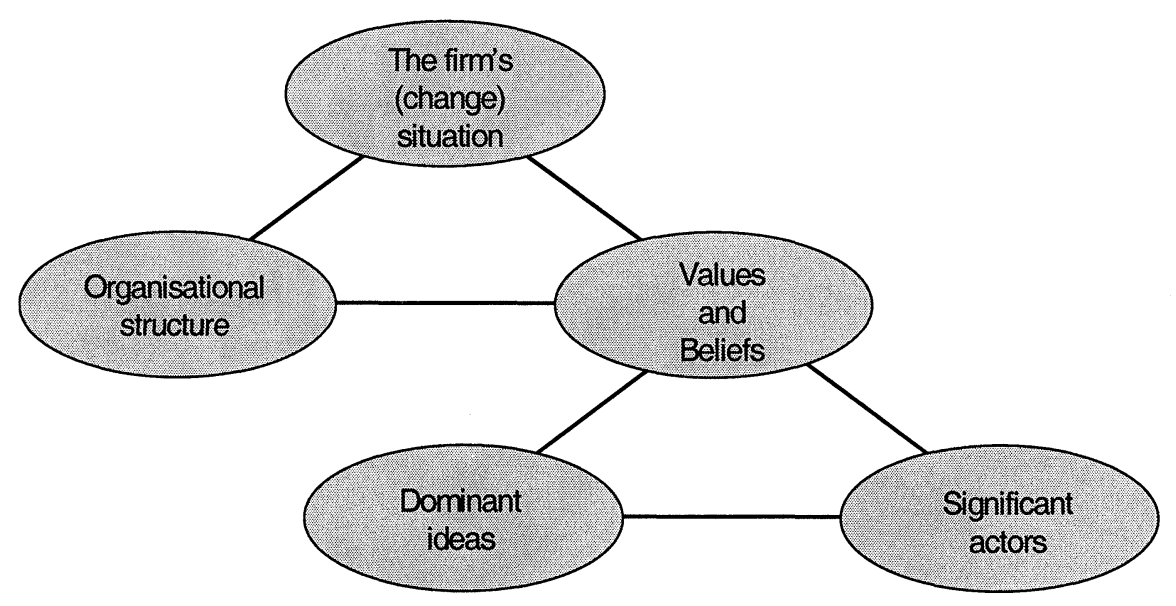

Figure 2. A model of a firm's strategic context (Adapted from Normann, 1975)

The reasoning in relation to Figure 2 can be seen as somewhat analogue to the structurational model of technology, brought forward by Orlikowski \& Robey (1991), with the difference that we do not consider information technology as a stand-alone phenomenon, but an integrated dimension of the organisational structure. 
To conclude, we cannot provide a complete model, stating appropriate actions for success when forming a strategy for e-business, but must accept the effects of contingencies. In the following section, a number of observations will be accounted for in order to give some examples of contingencies and e-business scenarios.

\section{OBSERVATIONS FROM THE E-BUSINESS SCENE}

Around the turn of the last millennium the notion of "dotcom death" came into everyone's mind, but not all companies entering the e-business scene was stroked by the "dotcom death". Some companies are still wealthy and expanding their business. But can some tendencies be seen that is sorting out the survivors, from those resting in the virtual graveyards? In order to found a ground for the further search on research directions about formulation of e-business efforts, a few cases those have been more or less successful in surviving on the e-business scene will be shortly described.

\subsection{Clas Ohlson}

A couple of years ago, word of mouth said that a bicycle repairman founded the biggest e-business company in Sweden back in 1918. Clas Ohlson, located in the small village of Insjön in middle Sweden, started its mail order operations by selling technical handbooks in the beginning of the 1920-s. In 2000 the annual turnover was approximately $140 \mathrm{M€}$ and the catalogue contains 15000 products ranging from welding sets and small compressors to shaving foam and paint for the hobby artist. What is common for all products is that they are sold to private consumers and institutions.

In 1996 Clas Ohlson launched their first web site and in 1999 they launched their new website where all products were available for sale. The launch of the website could be seen as logical step in the company's expansion, aiming at building a hybrid channels structure (Boberg \& Boborg 2001). In 1989 the company opened its first store outside Insjön, when they went into one of the most central gallerias in Stockholm. Since then another 21 stores has open in central location in major Swedish and Norwegian cities. Last year, 2001, the sales via Internet were about $35 \%$ of the total mail order sales, which in turn was around $13 \%$ of the total turn over. According to the company the sales via the web has attracted new customer groups like generally younger people and more women. But they don't think that their website will replace the catalogue, because you can bring it to all 
places in your home, as one company representative stated. The company see three different factors these positively have influenced the sales via the website. First, their base of 500000 customers; second they have a knowledge about logistics, meaning that at least $98 \%$ of the sold products should be delivered to the right place on the right time; third, the need for customer care, 20 people are working at the main location in Insjön to manage customer complaints.

\subsection{Net-on-Net}

Not only a prevailing customer base and infrastructure seems to be a way to remain on the e-business scene. Net-on-Net is a Swedish web based company selling home electronics and their turnover has grown from approximately $620000 €$ in 1999 , to approximately $18 \mathrm{M} €$ in 2001 , but they are still struggling to reach a profit. In 2000 the loss was $4 \mathrm{M} €$, but for the period January-November 2001 the losses had decreased to $2 \mathrm{M€}$, and according to the monthly report for November the company had 5,2 M€ in cash in hand and bank deposit. According to the company's CEO, companies like Net-on-Net, or pure dotcoms have during the last years, in order of turn over via the net, passed the traditional mail order companies, even if these are bigger in terms of total turn over. A further observation from the interview is that many of the dotcoms that survived, have been in businesses where the business models are similar to traditional mail order. A further interesting detail about Net-on-Net is its location in Borås, the home city of the major Swedish mail order companies since at least 50 years.

\subsection{Webvan and Disco}

Not only traditional mail order companies, or companies who start up on the Internet with concepts similar to mail order firms, have entered the ebusiness scene. Groceries have been a product where several attempts have been made. Two companies with a, at the first glance, similar concepts are Webvan and Disco. Webvan was an Internet grocer with a vision of creating 26 massive automated warehouses and a national fleet of vans that would deliver groceries in major US cities (Helft 2001). In order to gain success Webvan had built up a sophisticated logistic system to handle and deliver the right merchandise to the right place in the right time (Platoni 2001):

"The huge warehouse is a sci-fi workplace where the employees wear bar-code scanners on their fingertips and miniature wrist computers that tell them what to do, where the software driving the machinery is so prescient that it makes sure the potato chips get packed on top of the six-pack of Coke, instead of 
underneath. It is also the nerve center of Webvan's Bay Area hub-and-spoke routing system, designed to time deliveries so precisely that your order gets to your house with the ice cream still frozen and the tomatoes unblemished."

Webvan invested heavily in their infrastructure and their website was also regarded as "best of class", but they ran out of money and had to close down in mid 2001 (Schubert \& Dettling 2002).

A company with a, at the first glance, similar concept as Webvan is Disco in Buenos Aires, Argentina, a 237-store unit of Dutch food conglomerate Royal Ahold. But there are more differences than similarities between Disco and Webvan (Helft 2001):

Disco has built the business without the massive customized warehouses and automated distribution systems that cost Webvan hundreds of millions of dollars. Instead, it based the operation on a service that Disco has offered for decades: home delivery. Last year, about 25 percent of Disco's $\$ 2.5$ billion in sales were delivered. "We have been intimately familiar with the workings and the economics of the home delivery business for a long time," says Pablo García Gili, CEO of Disco's online division Disco Virtual. Another big difference: Disco execs were quick to recognize the discomfort Argentines have with punching their credit card numbers into a computer. Unlike Americans who use Webvan, Disco customers can pay for deliveries with cash or credit cards when the groceries arrive.

However, the virtual branch of Disco share one similarity with Webvan, it has yet to turn to a profit.

\subsection{E-commerce in Scandinavia}

A further clue to which kind of companies who can survive on the net might found if it is investigated what is sold on the net. A study of how much of the total sales volumes for different product groups that was sold via the Internet in Scandinavia in 2000 is shown in Table 5:

\begin{tabular}{|l|l|}
\hline Computer software & $18,2 \%$ \\
\hline Computer accessories & $12,8 \%$ \\
\hline PC's & $10,6 \%$ \\
\hline Music CD's & $8,7 \%$ \\
\hline Books & $4,5 \%$ \\
\hline Video movies & $3,9 \%$ \\
\hline Travels & $2,4 \%$ \\
\hline Toys & $1,6 \%$ \\
\hline Garment & $0,5 \%$ \\
\hline Groceries & $0,2 \%$ \\
\hline
\end{tabular}

Table 5. Percentage of sales volume via Internet of total sales volume in Scandinavia 2000 (Jansson 2000) 
The observations until now show that tangible goods sold before via mail order, is now also selling well via the net. But selling tangible goods is not a guarantee for survival, which Webvan is an example of. Another example of a company trying to sell tangible goods was Boo.Com, who through its existence burnt about $180 \mathrm{M} €$ of venture capital (The Irish times 2000). In May 1999 the online sportswear company was launched. The idea was to sell high-end garment via the Internet and retail sites was opened up in 18 countries. But due to technical problems it lasted until November 1999 before the sites were up and running. During its short life Boo.com struggled with financial problems and 17:th of May 2000 the company went bankrupt. The web site of Boo.com was technically rather advanced, but the problem was that it required a high bandwidth that made it too slow for many potential customers. (Glick 2000)

\subsection{Intangibles: Lovesearch}

However, not only companies selling tangible goods has survived, the net dating site "Lovesearch", which had the American site Match.com as a prototype, has also survived the dotcom death. Lovesearch opened up in the end of 1999 and was founded by the former member of the pop group Army of Lovers, Dominika Peczynski and the fashion designer Camilla Thulin. The members of the site are paying a member fee of $10 €$ per month. The service is built upon the members' input of information and characteristics about themselves, and characteristics the member wants of the potential partner. Then the computer is doing the job by matching together members with similar preferences and they can send messages or chat with each other. However, Lovesearch was not only built around the matchmaking site. The venture capitalist behind the site is Scandinavian Broadcasting Group who owns the Swedish channel 5, and the intention behind their engagement was to link the site to the companies TV-and radio stations (Edling 2001). One expression for this was the fact that one of the site founders, Dominika Peczynski, was host in Channel 5 for a program called Dating.

The description of the cases has showed that not only mail order companies have managed to survive the dotcom death. Even pure dotcoms selling tangible and intangible goods have survived, while other dotcoms who tried to sell tangible goods are resting in peace. In the next section, observations from the e-business arena will be discussed with regards to the theoretical framework in order to indicate what dimensions are important to relate to when considering e-business efforts. 


\section{EVOLUTION AS A BEST PRACTICE IN E- STRATEGY?}

In order to create a deeper understanding of the integration of a firm's overall strategy and its e-business efforts, the point of departure will be taken in the conception of a company's business idea and an elaboration of the three questions: what, to whom and how? The relation between who and what can be seen to reflect the classical relation between supply and demand, and how determines whether there will be a transaction or not. But the notion of how in the business idea should not only be understood as how the offer is delivered to the customer, if it is via mail order, store or another kind of delivery channel. The notion of how can also have a bearing on what the customer is buying. As stated above, a customer does not pay for a product, but for a perceived value. This expectation of value can of course in many cases be fulfilled, but in many other cases customers perceive value in some dimension that goes beyond the core product. This might be one explanation to why companies like Boo.com failed. Customers not only want to buy high-end fashion garments, they also want the pleasure involved in a shopping experience. This explanation is more or less exclusively directed towards the actual product offer, the "what part". A discussion on the "how part" leads us to an understanding of consumer behaviour. There are not many examples of successful mail order firms selling high-end fashion; it might be so that the target markets for these products do not consider mail order as a shopping alternative. If you cannot sell these products via traditional mail order, why should you be able to do so just because you place the catalogue on the Internet?

However, even if consumer behaviour is an important issue whether an ebusiness effort will survive or not, it will not per se determine a success. A comparison between Webvan and Disco shows the context dependency. Disco is operating in a market where home delivery of groceries is well established since many years and they also adapted to customers scepticism about paying with credit cards via Internet. At the same time one can raise the question if Webvan had the appropriate knowledge about consumer behaviour in their target market?

Clas Ohlson is a good example of a development strategy that is consistent with the existing business idea. They had a long tradition of selling their product portfolio via traditional mail order. Both the assortment as well as the mail order system with infrastructures for information and goods was well suited in order to provide an established mass of customers with a value. The extension into the e-business arena was not a huge step for Clas Ohlson, since the back bone logistics and the customer handling system was already in place. There was no conflict with the traditional values and 
beliefs in the firm, since the basic logic of operations was the same. One could in fact argue that the opening of physical stores was a harder step to take, since that strategic choice implied a new direction and focus of the firm's core competencies.

Compared to mail order companies solely present on the Internet, as Neton-Net, Clas Ohlson has, at the moment, an advantage of a financial strength based on the turnover in their traditional stores, which makes them less vulnerable for losses in their e-business branch. The same situation can be said to be present for Disco who can relay on the turnover from their traditional store, and allow them to find out how an e-business effort can be integrated into the overall strategy.

In the case of Lovesearch it can be claimed that the company has added a value compared to more traditional match making services. The customer doesn't have to wait several days for answers regarding potential partners and the chat and message function makes it possible to immediately get in touch with the other person. However, one might raise the issue whether the survival until now depends on the value adding services those are provided by Lovesearch, or if it depends upon the marketing efforts with the celebrities and the TV-channel involved? Or is it a combination of both these circumstances?

\section{CONCLUSIONS}

Even though one can argue that our empirical observations are not characterised by the depth needed in order to make clear normative statements about strategy formation, we do believe that we can use the analysis above to indicate topics of importance when considering e-business efforts. Naturally, this is based on our approach that even though some scholars believe that we experience new logic in the economy we still believe in some basic strategic virtues. The basic premise for survival is that a firm can provide value to someone outside the firm, a statement that is supported by the limited empirical observations in this paper.

A problem is though how to combine intentions with the influence of contingencies. If a strategic decision situation is context dependent and contingent, is it ever possible to give recommendation for managers...? Of course not in terms of detailed action plans, but we will here point out some issues that have to be dealt with: 


\subsection{A clear conception of the target market}

First of all, all customers are not all alike and do not possess the same needs, wants and demands. Hence, there is a need for a clear conception of the target market of the firm, and an understanding of what kind of problems that can be solved for these customers.

\subsection{A consistency between the defined market and the product system to be sold}

If there is a defined target market and the needs, wants and demands of this market are defined as well; there is a possibility to define a product system to be sold to this market. The most important thing to remember here is that customers basically do not care about products and services as such, but the problem solution these products offer.

In most cases, the Internet as such does not provide a problem solution but function merely as a media for transactions. There are of course other cases, where the basic problem solution can be defined in terms of convenience, accessibility, time and other dimensions and the Internet is the best mean in order to achieve this. It is however important to understand the fundamental behaviour of the target market in relation to the specific product class, when determining the problem solution to be sold.

\subsection{An understanding of the relation between market, product and the delivery/communication system}

With a defined target market, a definition of problems to be solved and a defined problem solution, the way to make this happen needs to be defined. Even though it is impossible to define an absolute best practice, there has to be a consistency between market, product and the set of competencies, resources, supporting infrastructures and technologies used. Even though a firm might have a "perfect solution" to be sold on "the best web site", this way to sell the product has to make sense for the customer, otherwise there will be no sale. Some products are very hard to sell via mail order. These products will be hard to sell on the net as well, if it is perceived as mail order upgraded by an electronic brochure. 


\subsection{Act on the values and beliefs of the organisation}

This final recommendation might be the most important, but at the same time the most difficult to relate to. When facing a situation of an intended strategic change, one has to understand the importance of the tradition and history of the firm. There are a lot of cognitive understandings of the firm's identity and it's raison d'être guiding future conceptions of the firm's activities. Any e-business effort intended needs to be consistent with this understanding of the firm, besides the need for consistency with competencies, resources and structures. The reason for this can be found in the fact that any firm has its tradition and a cognitive perception of this tradition among the staff. If there for example is a dominant idea that the firm is not a mail order firm, an e-commerce development will not make sense to the staff if it is perceived as electronic mail order. The most likely consequence will be that even if this electronic ordering system is introduced, the organization will act on the values and beliefs underlying the tradition of not being a mail order firm. In that case, actions in the firm might not be consistent with the way the firm approach the market.

\section{REFERENCES}

Boberg, P, \& Boborg, N. (2001) Just add .se: Old companies in a new situation - A qualitative study of hybrid channel structures. Master's Thesis. Dept of Business Administration Umeå University.

Brache \& Webb (2000) The eight deadly assumptions of e-business. Journal of Business Strategy 21(3), 13-17.

Campbell, A \& Yeung, S. (1991) Brief Case: Mission, Vision and Strategic Intent Long Range Planning, Aug 1991

Chandler, A D. Jr. (1962) Strategy and structure: chapters in the history of the American industrial enterprise. Cambridge, MA: MIT Press.

Coupey, E. (2001) Marketing and the Internet - Conceptual Foundations. Upper Saddle River, NJ. Prentice Hall.

Davidsson, P. (1989); Continued Entrepreneurship and Small Firm Growth. Stockholm: Ekonomiska Forskningsinstitutet.

Davidsson, P. (1996); Kultur och företagande. in Johannisson, B., Lindmark, L. editors.Företag, Företagare, Företagsamhet. Studentlitteratur, Lund. p. 151-73.

Edling, L (2001) Hon gör affärer på Internet. www.aftonbladet.se/vss/ekonomie24/story/ $0,2789,24459,00 . h t m l(020225)$

Evans, P \& Wurster, T.S. (2000) Blown to bits - How the new economics of information transforms strategy. Harvard business school press. Boston.

Glick, B. (2000); boo.com's fall makes realism the fashion. http://www.vnunet.com/ Analysis/1102339

Hackbart, G \& Kettinger W. J. (2000) Building an E-business strategy. Information Systems Management 17(3), 78-93. 
Hamel, G, Doz, Y.L., Prahalad, C.K. (1989) Collaborate with your Competitors and Win. Harvard Business Review. Jan-Feb. 1989:133-139.

Heft, D. (2001) Don't Cry for Argentina's Version of Webvan. www.thestandard.com /article/0,1902,24050,00.html

Mintzberg, H, Ahlstrand, B, Lampel, J. (1998) Strategy Safari. Hemel Hempstead. Prentice Hall.

Normann, R. (1975) Skapande Företagsledning. Arlöv. Bonniers.

Orlikowski, W J. \& Robey, D. (1991) Information technology and structuring of organizations. Information Systems Research. 2(2), 143-169.

Platoni, K. (2001) The Last Mile. In: East Bay Express online. http://www.eastbayexpress. com/issues/2001-05-25/feature.htm1/1/index.html

Schubert, P, \& Dettling, W. (2002) Extended Web Assessment Method (EWAM) Evaluation of E-commerce Application from the Customer's Viewpoint. In: Proceedings of the 35th Hawaii International Conference on Systems Sciences.

Searle, J R. (1995) The construction of social reality. London. Penguin Books.

The Irish times (2000); Boo.com - like selling fresh air, claims liquidator. http://www.ireland .com/newspaper/breaking/2000/0602/breaking42.htm

Thong, J.Y. and Yap, C.S. (1995); An information technology adoption model for small businesses. in Kautz, K., Pries-Heje, J., Larsen, T.J., Sörgaard, P. editors.Conference Notebook: First IFIP 8.6 Working Conference on Diffusion and Adoption of Information Technology. Norsk Regnesentral, Oslo. p. 349-64. 